\title{
Detailed Measurements of ECCD Efficiency on DIII-D for Comparison with Theory
}

C.C. Petty, R. Prater, J. Lohr, T.C. Luce, R.A. Ellis, R.W. Harvey, J.E. Kinsey, L.L. Lao, M.A. Makowski

This article was submitted to: $12^{\text {th }}$ Joint Workshop on Electron Cyclotron Emission and Electron Cyclotron Resonance Heating, Aix-en-Provence, France 5/13-5/16/02

May 1, 2002

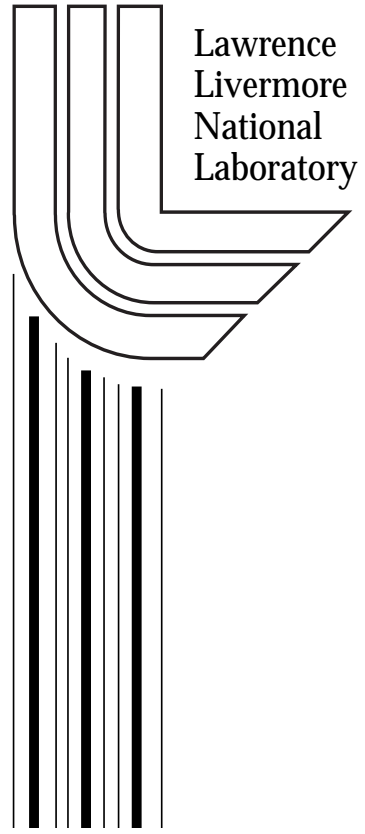




\section{DISCLAIMER}

This document was prepared as an account of work sponsored by an agency of the United States Government. Neither the United States Government nor the University of California nor any of their employees, makes any warranty, express or implied, or assumes any legal liability or responsibility for the accuracy, completeness, or usefulness of any information, apparatus, product, or process disclosed, or represents that its use would not infringe privately owned rights. Reference herein to any specific commercial product, process, or service by trade name, trademark, manufacturer, or otherwise, does not necessarily constitute or imply its endorsement, recommendation, or favoring by the United States Government or the University of California. The views and opinions of authors expressed herein do not necessarily state or reflect those of the United States Government or the University of California, and shall not be used for advertising or product endorsement purposes.

This is a preprint of a paper intended for publication in a journal or proceedings. Since changes may be made before publication, this preprint is made available with the understanding that it will not be cited or reproduced without the permission of the author.

This work was performed under the auspices of the United States Department of Energy by the University of California, Lawrence Livermore National Laboratory under contract No. W-7405-Eng-48.

This report has been reproduced directly from the best available copy.

Available electronically at http://www.doc.gov/bridge

Available for a processing fee to U.S. Department of Energy

And its contractors in paper from

U.S. Department of Energy

Office of Scientific and Technical Information

P.O. Box 62

Oak Ridge, TN 37831-0062

Telephone: (865) 576-8401

Facsimile: (865) 576-5728

E-mail: reports@adonis.osti.gov

Available for the sale to the public from

U.S. Department of Commerce

National Technical Information Service

5285 Port Royal Road

Springfield, VA 22161

Telephone: (800) 553-6847

Facsimile: (703) 605-6900

E-mail: orders@ntis.fedworld.gov

Online ordering: http://www.ntis.gov/ordering.htm

OR

Lawrence Livermore National Laboratory

Technical Information Department's Digital Library

http://www.llnl.gov/tid/Library.html 


\title{
DETAILED MEASUREMENTS OF ECCD EFFICIENCY ON DIII-D FOR COMPARISON WITH THEORY
}

\author{
C.C. Petty, ${ }^{1}$ R. Prater, ${ }^{1}$ J. Lohr, ${ }^{1}$ T.C. Luce, ${ }^{1}$ R.A. Ellis,${ }^{2}$ R.W. Harvey, ${ }^{3}$ \\ J.E. Kinsey, ${ }^{4}$ L.L. Lao, ${ }^{1}$ and M.A. Makowski ${ }^{5}$ \\ ${ }^{1}$ General Atomics, P.O. Box 85608, San Diego, California 92186-5608 \\ 2 Princeton Plasma Physics Laboratory, P.O. Box 451, Princeton, New Jersey 08543-0451 \\ ${ }^{3}$ CompX, P.O. Box 2672, Del Mar, California $92014-5672$ \\ ${ }^{4}$ Lehigh University, Bethlehem, Pennsylvania 18015 \\ ${ }^{5}$ Lawrence Livermore National Laboratory, P.O. Box 808 Livermore, California 94551
}

\begin{abstract}
Recent experiments on the DIII-D tokamak have focused on determining the effect of trapped particles on the electron cyclotron current drive (ECCD) efficiency. Localized power deposition and current drive were observed for both L-mode and ELMing $\mathrm{H}$-mode plasmas. The ECCD efficiency was measured for both co and counter injection. Overall, the experimental ECCD efficiency was in good agreement with the CQL3D Fokker-Planck model over a wide range of injection angles and plasma parameters.
\end{abstract}

\section{Introduction}

Electron cyclotron current drive (ECCD) experiments on the DIII-D tokamak are solidifying the physics basis for localized, off-axis current drive, the goal being to validate a predictive model for ECCD. Using internal magnetic measurements from motional Stark effect (MSE) polarimetry, driven currents as small at $1 \%$ of the total plasma current can be accurately measured. As a result, the physics of ECCD can be explored in unprecedented detail since the ECCD efficiency can be determined over a wide range of plasma conditions. Two separate methods have been used to deduce the ECCD from the MSE signals. In the first method, the non-inductive current drive was determined from the evolution of the poloidal magnetic flux obtained from a magnetic equilibrium reconstruction constrained by the MSE data $[1,2]$. In the second method, the measured MSE signals were compared to simulations of the MSE evolution using a model of the ECCD profile [3]. The parameters of the model location, width, and magnitude - were adjusted until a best fit between the measured and simulated MSE signals was obtained. In this paper, the ECCD results were obtained using the second method exclusively.

\section{Polarization Verification}

These ECCD experiments were done on the DIII-D tokamak, typical parameters for which were major radius $\mathrm{R}=1.7 \mathrm{~m}$, minor radius $\mathrm{a}=0.6 \mathrm{~m}$, elongation $\kappa=1.8$, toroidal magnetic field strength $\mathrm{B}_{\mathrm{T}}=1.65-2.15 \mathrm{~T}$, and plasma current $\mathrm{I}_{\mathrm{p}}=0.6-1.3 \mathrm{MA}$. These experiments used up to four gyrotron oscillators operating at $110 \mathrm{GHz}$, with a maximum combined power of 2.1 MW injected into the plasma [4-6]. The polarization corresponding to the $\mathrm{X}$-mode dispersion relation was launched in these experiments since it was absorbed strongly at the second harmonic resonance. The $\mathrm{X}$-mode polarization of the launched electron cyclotron waves has been confirmed for radial launch in L-mode plasmas [7].

As shown in Fig. 1, the expected polarization was verified for the first time using electron cyclotron waves launched at an oblique angle in an ELMing $\mathrm{H}$-mode plasma. This was an important test since the steep density gradient in the $\mathrm{H}$-mode edge region could possibly prevent the efficient coupling of the waves because the density scale length was on the order of the electron cyclotron wavelength. Furthermore, during an ELM, the electron cyclotron wave could possibly suffer a density cut off for the low field launch. Evidence for these 

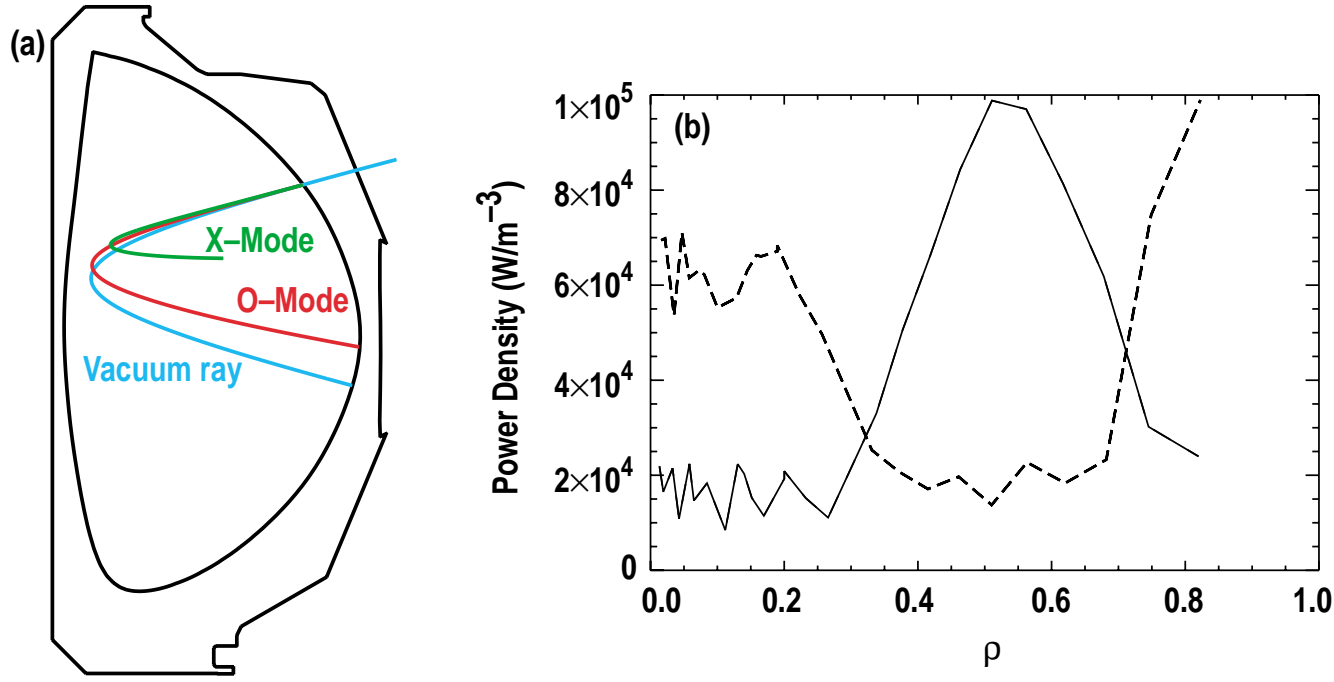

Fig. 1. (a) Ray paths for vacuum, $X$-mode, and $O$-mode, and (b) experimental power deposition profile for $X$-mode (solid) and O-mode (dashed) launch.

effects would be the detection of the wrong wave polarization or a scrambled power deposition profile. Figure 1(a) shows how the wave polarization can be found from the deposition location since the wave refraction for $\mathrm{X}$-mode and $\mathrm{O}$-mode calculated using the Toray-GA ray tracing code $[8,9]$ is different. The power density profiles measured using modulation techniques are shown in Fig. 1(b) for X-mode (solid) and O-mode (dashed) launch for the case where the resonance passes through the plasma axis. Figure 1 shows that the launched polarization of the electron cyclotron waves was not altered by the steep density gradient of the $\mathrm{H}$-mode and the deposition profile was not scrambled by the ELMs. Thus, the edge region of $\mathrm{H}$-mode plasmas should have no deleterious effects on ECCD.

\section{Comparison of Experimental and Theoretical ECCD}

The goal of these ECCD experiments was to validate a predictive model of ECCD as calculated by the CQL3D code [10], including the effects of the parallel electric field $\mathrm{E}_{\|}$. The main tenets of quasilinear Fokker-Planck theory were examined by determining the current drive dependences on (a) the parallel index of refraction $\mathrm{N}_{\|}$, (b) the poloidal deposition location $\theta_{\text {pol }}$, (c) the normalized radius of deposition $\rho$, and (d) the electron beta $\beta_{\mathrm{e}}$. Previous publications showed that the ECCD efficiency for off-axis deposition increased with increasing $\beta_{\mathrm{e}}$ due to a reduction in the trapping effects [11,12]. Therefore, this paper concentrates on the $\mathrm{N}_{\|}, \theta_{\text {pol }}$, and $\rho$ dependences of the ECCD efficiency for different $\beta_{\mathrm{e}}$. Since many of these experiments vary the electron density and temperature, it is convenient to normalize out the usual power per particle and collisionality effects when discussing the current drive efficiency, resulting in a dimensionless ECCD efficiency given by

$$
\zeta_{\mathrm{ec}}=\frac{\mathrm{e}^{3}}{\varepsilon_{0}^{2}} \frac{\mathrm{I}_{\mathrm{ec}} \mathrm{Rn}_{\mathrm{e}}}{\mathrm{P}_{\mathrm{ec}} \mathrm{kT}_{\mathrm{e}}}=3.27 \frac{\mathrm{I}_{\mathrm{ec}}(\mathrm{A}) \mathrm{R}(\mathrm{m}) \mathrm{n}_{19}}{\mathrm{P}_{\mathrm{ec}}(\mathrm{W}) \mathrm{T}_{\mathrm{e}}(\mathrm{keV})},
$$

Figure 2 shows that a scan of $\mathrm{N}_{\|}$from positive to negative values switched the ECCD from the co to the counter direction, with radial injection $\left(\mathrm{N}_{\|}=0\right)$ driving little current. The measured $\zeta_{\mathrm{ec}}$ at fixed $\rho$ and $\theta_{\mathrm{pol}}$ increased with larger $\left|\mathrm{N}_{\|}\right|$for both co and counter injection, as expected theoretically since the electron cyclotron waves interacted with higher parallel velocity electrons. The saturated ECCD efficiency was largest for the highest $\beta_{\mathrm{e}}$ case, in agreement with the favorable beta scaling of $\zeta_{\mathrm{ec}}$ measured previously on DIII-D. The measured values of $\zeta_{\mathrm{ec}}$ for the $\mathrm{N}_{\|}$scans was in agreement with the CQL3D Fokker-Planck modeling, including the effect of $\mathrm{E}_{\|}$. 
The effect of electron trapping on $\zeta_{\mathrm{ec}}$ was investigated by varying the poloidal location of the ECCD deposition. This was effective because the local trapped particle fraction varies from small near the inboard midplane $\left(\theta_{\mathrm{pol}}=180^{\circ}\right)$ to maximum at the outboard midplane $\left(\theta_{\text {pol }}=0^{\circ}\right)$. Figure 3 shows that the measured $\zeta_{\text {ec }}$ increased as the poloidal location of deposition was moved towards the inboard side at fixed $\rho$ and $\mathrm{N}_{\|}$. This effect was especially apparent in low $\beta_{\mathrm{e}}$ plasmas, while the $\theta_{\text {pol }}$ dependence for high $\beta_{\mathrm{e}}$ plasmas was weaker due to the reduced trapping effect at high electron density and temperature. In addition, the $\theta_{\text {pol }}$ dependence of $\zeta_{\mathrm{ec}}$ was stronger at larger $\rho$. The experimental data in Fig. 3 was in agreement with the $\theta_{\text {pol }}$ dependence predicted by the CQL3D code, including the effect of $\mathrm{E}_{\|}$, for both co and counter injection. Therefore, it was easiest to drive current off-axis when the ECCD location was on the high magnetic field side of the plasma.

Another effect of electron trapping is that $\zeta_{\mathrm{ec}}$ should decrease with increasing $\rho$ because the trapped particle fraction increases with increasing inverse aspect ratio. Figure 4 shows that for low beta plasmas, the measured $\zeta_{\mathrm{ec}}$ decreased rapidly with increasing radius (above the axis) for both co and counter injection. The role of electron trapping was confirmed by the radial scan on the inboard midplane in high beta plasmas also shown in Fig. 4, where the measured $\zeta_{\mathrm{ec}}$ decreased more slowly with increasing $\rho$. The theoretical ECCD efficiency from the CQL3D code, including the effect of $E_{\|}$, was in agreement with the experiment for both the strong trapping and weak trapping situations. Thus, current profile control with offaxis ECCD was more favorable in high $\beta_{\mathrm{e}}$ plasmas since the ECCD efficiency does not decrease as much with radius.

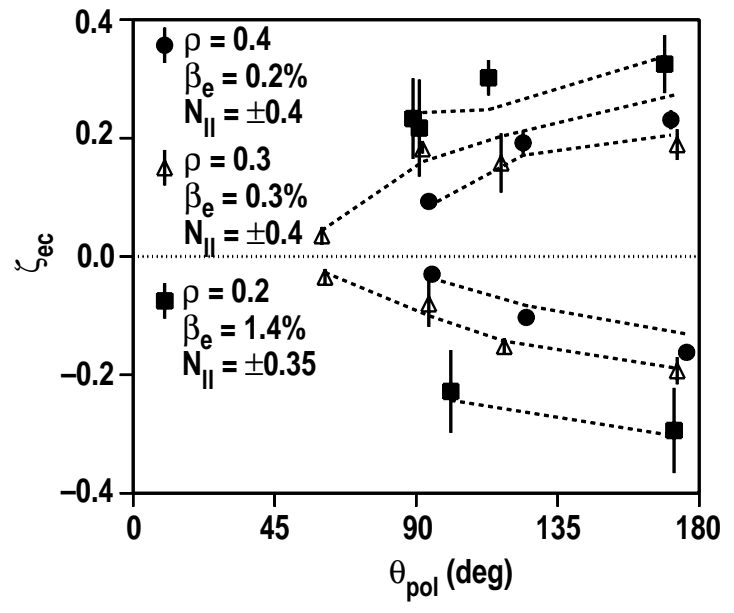

Fig. 3. Experimental dependence of the dimensionless ECCD efficiency on of the poloidal angle of deposition. The theoretical dependence calculated by the CQL3D code is also shown (dashed lines).

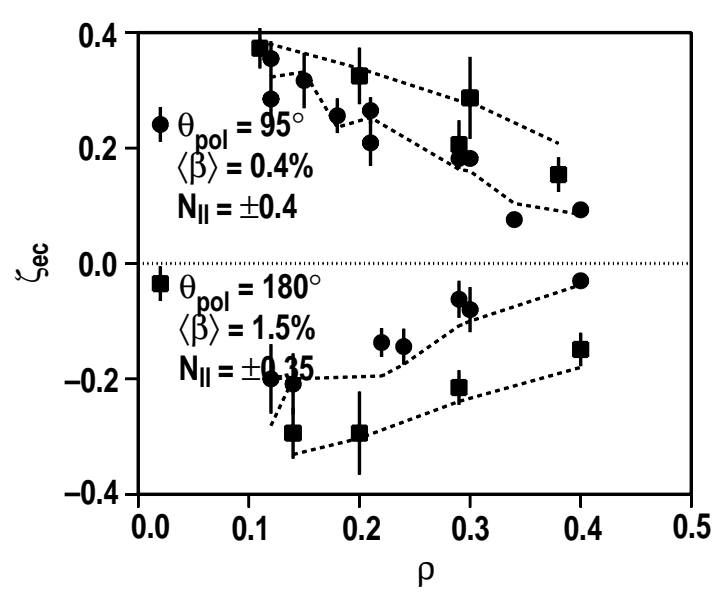

Fig. 4. Measured dimensionless ECCD efficiency for scans of the normalized radius of deposition. The theoretical dependence calculated by the CQL3D code is also shown (dashed lines). 
The experimental ECCD (both co and counter) for the entire DIII-D data set, including scans over $\mathrm{N}_{\|}, \theta_{\mathrm{pol}}, \rho$, and $\beta_{\mathrm{e}}$, is compared to linear theory in Fig. 5 and quasilinear FokkerPlanck calculations in Fig. 6. A statistical comparison between the linear Toray-GA code and the ECCD measurements in Fig. 5 yielded a reduced $\chi^{2}$ of 5.4, while the reduced $\chi^{2}$ decreased to 1.2 for the CQL3D code in Fig. 6. Therefore, the more complete quasilinear Fokker-Planck theory of ECCD, including the effect of $\mathrm{E}_{\|}$, was the better predictor of the experimental ECCD efficiency.

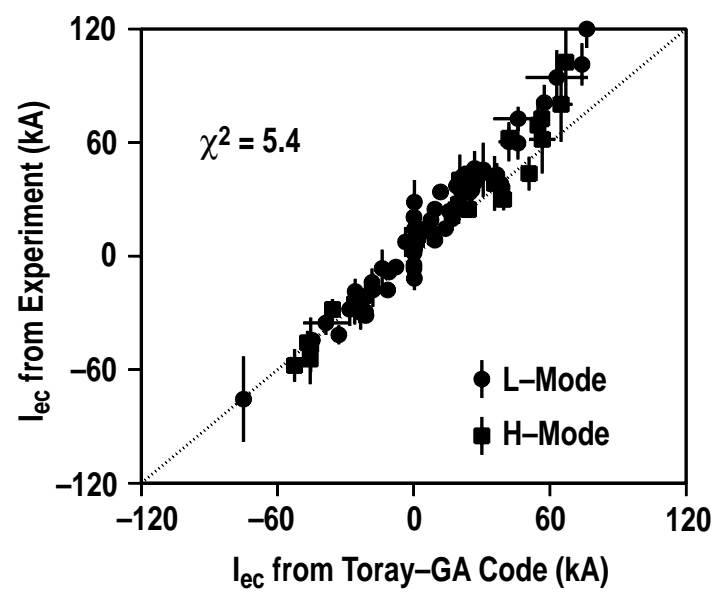

Fig. 5. Comparison of measured and theoretical ECCD over a range of parameters. The theoretical ECCD is calculated using linear theory.

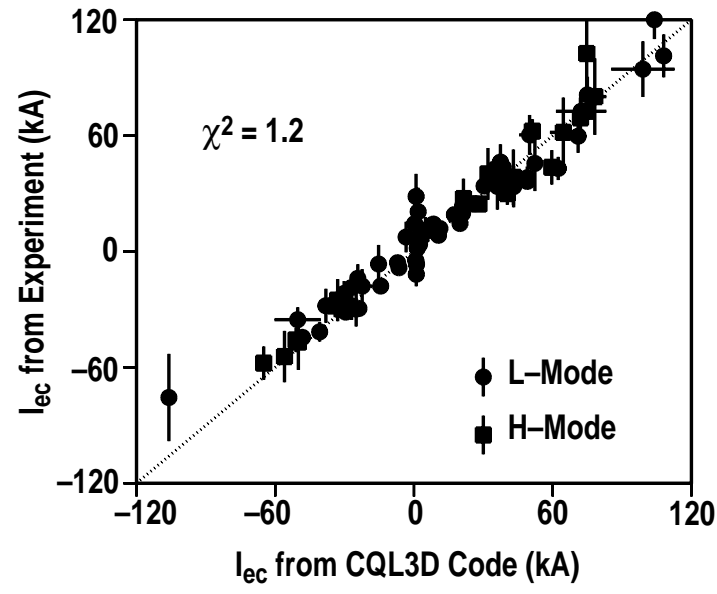

Fig. 6. Comparison of measured and theoretical ECCD over a range of parameters. The theoretical ECCD is calculated using quasilinear FokkerPlanck theory including the effect of $E_{\|}$.

\section{Conclusions}

The physics basis for localized, off-axis current drive has been solidified by recent ECCD experiments on the DIII-D tokamak. No deleterious effects from the H-mode edge region were observed in the electron cyclotron wave polarization or deposition. The measured ECCD switched from the co to the counter direction as the toroidal injection angle was varied. Tests of electron trapping in low beta plasmas showed that the ECCD efficiency decreased rapidly as the deposition was moved off-axis and towards the outboard side of the plasma, but the detrimental effects of electron trapping on the current drive were greatly reduced in high beta plasmas. The measured ECCD was in good agreement with quasilinear Fokker-Planck calculations, including the effect of the parallel electric field, over a wide range of parameters.

\section{Acknowledgment}

Work supported by U.S. Department of Energy under Contracts DE-AC03-99ER54463, W-7405-ENG-48, DE-AC02-76CH03073, and Grants DE-FG03-99ER54541 and DE-FG0292ER54141.

\section{References}

[1] Forest, C.B., et al., Phys. Rev. Lett. 73 (1994) 2444.

[2] Lao, L.L., et al., in Radiofrequency Power in Plasmas (Proc. 14th Int. Conf. Oxnard, 2001), AIP, New York (2001) 310.

[3] Petty, C.C., et al., Nucl. Fusion 41 (2001) 551. 
[4] Callis, R.W., et al., in Fusion Technol. (Proc. 20th Symp. Marseille, 1998), Vol. 1, Association EURATOM-CEA, Saint-Paul-Lez-Durance (1998) 315.

[5] Lohr, J., et al., in Infrared and Millimeter Waves (Proc. 23rd Int. Conf. Colchester, 1998), University of Essex, Colchester (1998) 269.

[6] Lohr, J., et al., in Radiofrequency Power in Plasmas (Proc. 14th Int. Conf. Oxnard, 2001), AIP, New York (2001) 314.

[7] Petty, C.C., et al., in Strong Microwaves in Plasmas (Proc. 4th Int. Conf. Nizhny Novgorod, 1999), Vol. 1, Russian Academy of Sciences, Nizhny Novgorod (2000) 41.

[8] Matsuda, K., IEEE Trans. Plasma Sci. 17 (1989) 6.

[9] Lin-Liu, Y.R., et al., in Controlled Fusion and Plasma Physics (Proc. 26th Eur. Conf. Maastricht, 1999), Vol. 23J, European Physical Society, Geneva (1999) 1245.

[10] Harvey, R.W., McCoy, M.G., in Proceedings of the IAEA Technical Committee Meeting, Montreal, 1992 (IAEA, Vienna, 1993) 498.

[11] Petty, C.C., et al., in Radiofrequency Power in Plasmas (Proc. 14th Int. Conf. Oxnard, 2001), AIP, New York (2001) 275.

[12] Petty, C.C., et al., in Controlled Fusion and Plasma Physics (Proc. 28th Eur. Conf. Funchal, 2001), Vol. 25A, European Physical Society, Geneva (2001) 1161. 